\title{
Iguales en amor con
}

mal suceso: Dom Quixote e Orlando Furioso

PEDRO GARCEZ

GHIRARDI é professor

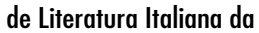
FFLCH-USP e ganhador

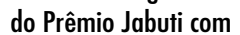
a traducão de Orlando Furioso de Ludovico Ariosto (Ateliê).

PEDRO GARCEZ GHIRARDI

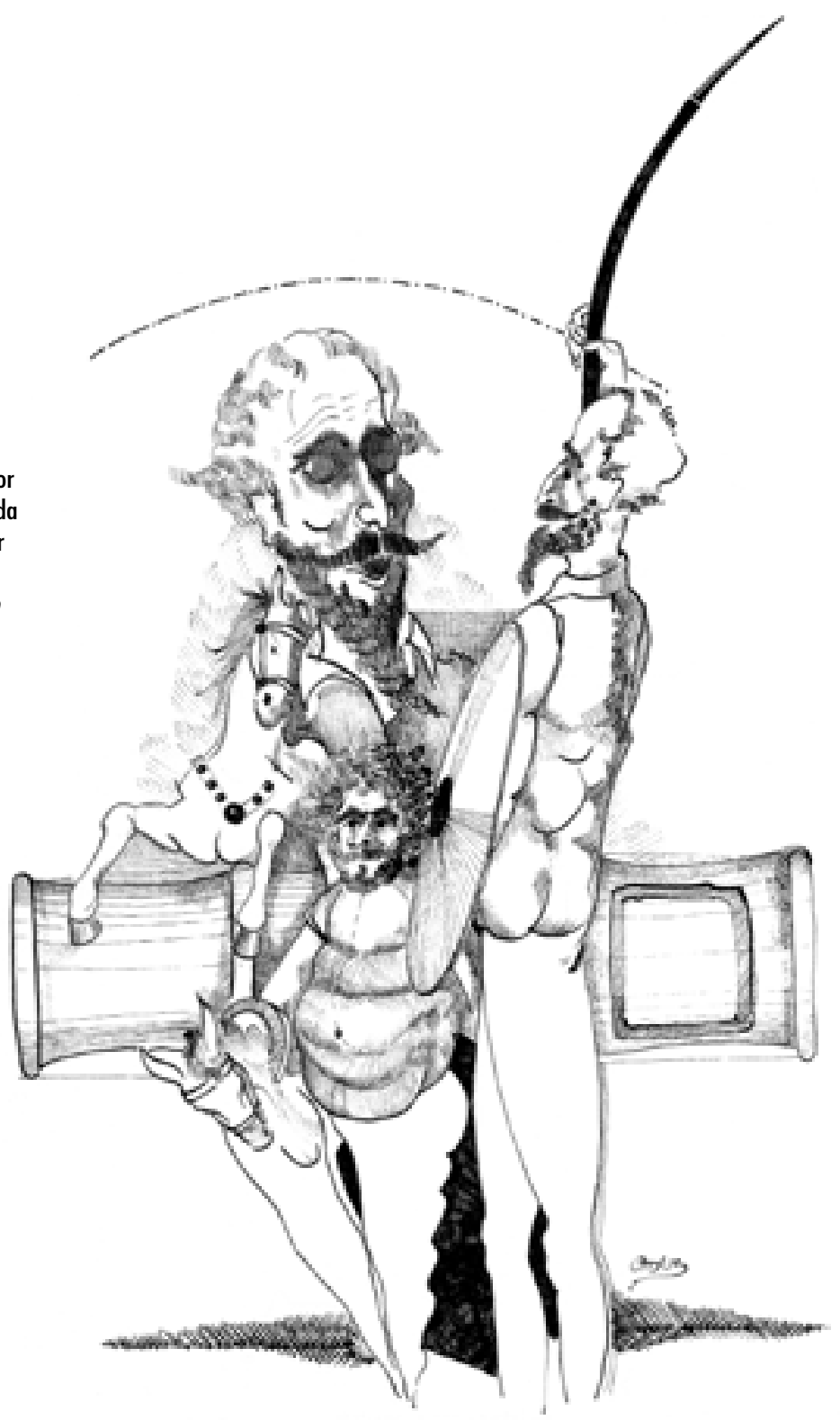




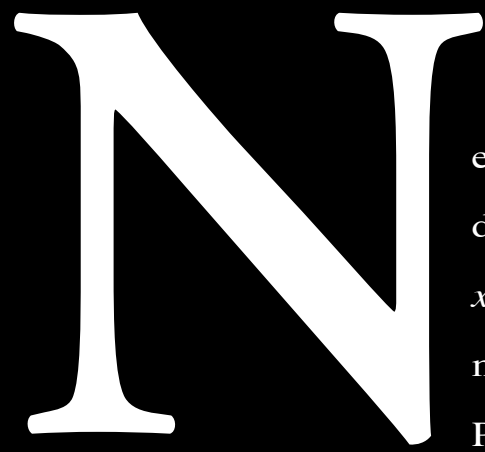

estes quatrocentos anos de existência, Dom Quixote tem percorrido os caminhos do mundo todo. Poucos livros terão tido tantos leitores e tantos críticos. Pode-se dizer que não há página e quase não há linha da obra de Cervantes que não haja suscitado comentários e análises (1). Como sabemos, uma biblioteca provinciana foi o berço de Dom Quixote. Seus livros sumiram-se por artes mágicas, ou melhor, por artes do cura e do barbeiro, mas foram, por sua vez, semente de muitos outros, todos dedicados às aventuras do cavaleiro e de seu inseparável escudeiro.

É a leitura, portanto, que transforma um pacato fidalgo no maior dos cavaleiros andantes. Mas a relação com os livros permeia toda a obra de Cervantes. É sabido que já na primeira saída Dom Quixote se imaginava futuro personagem de um texto escrito, como dizele em "los venideros tiempos, cuando venga a la luz la verdadera historia de mis famosos hechos" (I, 2). E é na parte final que isso assume plena evidência. É então que Dom Quixote e Sancho adquirem clara consciência de sua dimensão literária e travam relações freqüientes com seus leitores. Como ressalta Maria Augusta Vieira, esses leitores “discutem com Dom Quixote e Sancho episódios ocorridos na primeira parte" (2). 
O Quixote, portanto, como poucos outros, é um livro em diálogo com livros, um livro em que personagens têm consciência de que dialogam com personagens. E sinais desse diálogo se fazem presentes ainda antes da narrativa das aventuras quixotescas. Podemos encontrá-los em um dos recantos menos comentados da obra, os chamados versos preliminares.

Cervantes mesmo, no "Prólogo", nos conta como lhe teria ocorrido a composição dessas poesias. Seriam fruto do conselho de um amigo, que o animara a escrevêlas para suprir a falta de contemporâneos ilustres que se dispussem a apresentar a nova obra com os versos então de praxe. É verdade, diz também Cervantes, que seria possível encomendar esses versos "a dos o tres oficiales amigos", mas esta solução não parece animá-lo. Daí a idéia de aceitar o oportuno conselho: "Con silencio grande estuve escuchando lo que mi amigo me decía, y de tal manera se imprimieron em mí sus razones, que sin ponerlas en disputa las aprobé por buenas [...]" ("Prólogo"). Diante dessas palavras ficam menos fundadas algumas hesitações quanto à autoria cervantina desses versos. Basta notar que todos são atribuídos a personagens literários, precisamente como previa o conselho adotado.

A aparição de Dom Quixote, portanto, é anunciada por outros personagens da literatura, quase sempre ligados ao mundo da cavalaria. Mas dentre eles há um, em particular, que terá no romance lugar privilegiado. Trata-se de um cavaleiro, como Dom Quixote, também enamorado e também enlouquecido. Sua presença desponta nas décimas da feiticeira Urganda "la Desconocida”. Esses versos incompletos, ou de pé quebrado, são os primeiros que predizem a chegada de Dom Quixote. E já a predizem com uma importante referência literária. De fato, Urganda assim resume a obra que está para começar:

"De un noble hidalgo manchecontarás las aventu- damas, armas, caballele provocaron de moque, cual Orlando furio-, templado a lo enamora-, alcanzó a fuerza de bra-

a Dulcinea del Tobo-”

(Versos preliminares: "Al Libro de Don Quijote de la Mancha, Urganda la Desconocida”).

Essas palavras de Urganda apresentam Dom Quixote por meio da evocação de outra figura literária, Orlando. E por Orlando tal como se configurou na tradição poética italiana, que o fez enamorado em Boiardo e furioso em Ariosto: "cual Orlando furio-/ templado a lo enamora-". Dentro dessa tradição, é principalmente ao poema de Ariosto que Urganda se reporta. Na menção de “damas, armas, caballe-", o leitor é remetido aos primeiros versos do poema, justamente: “le donne, i cavalier, l'arme, gli amori”. Assim, desde o início se propõe o Orlando Furioso como uma das chaves de leitura do Quixote.

Por outro lado, essa proposta vem de Urganda, que, como se sabe, pertence ao ciclo dos romances cavalheirescos de Amadis de Gaula. Mas nesse momento a feiticeira se revela leitora do Orlando $F u$ rioso, cujos versos sabe até citar. Por outras palavras, Urganda revela que o mundo dos romances de cavalaria já se havia encontrado com o que Erich Auerbach chamava de "doce ironia" do poeta de Orlando (3). E desse encontro saíra transformado. Cervantes avisa o leitor do Quixote que a leitura das histórias de cavalaria não mais seria a mesma depois de passar pelo sorriso transformador de Ariosto.

A importância dessa referência inicial confirma-se quando, nas páginas seguintes, $o$ próprio Orlando Furioso aparece entre os que apresentam Dom Quixote aos leitores. Ele o faz por meio de um soneto de homenagem, em que a vida e as aventuras do Quixote são comparadas com as suas e, afinal, declaradas superiores. O soneto é este:

"Si no eres par, tampoco le has tenido: que par pudieras ser entre mil pares, 
ni puede haberle donde tu te hallares, invicto vencedor, jamás vencido.

Orlando soy, Quijote, que perdido por Angélica vi remotos mares, ofreciendo a la Fama en sus altares aquel valor que respetó el olvido. No puedo ser tu igual, que este decoro se debe a tus proezas y a tu fama, puesto que, como yo, perdiste el seso; mas ser lo has mío, si al soberbio moro y cita fiero domas, que hoy nos llama iguales en amor con mal suceso" (Versos preliminares: "Orlando Furioso a Don Quijote de la Mancha”).

Esse soneto merece também maior atenção da crítica. Vimos que Cervantes cria personagens que têm consciência de sua vida literária e que dialogam sobre essa vida. Vimos ainda que, embora isso ocorra de modo especial na segunda parte do romance, não faltam na primeira parte indícios de que essa criação estava desde o começo nos propósitos do autor. Um desses indícios parece ser esse soneto. Seus versos falam dos feitos de Dom Quixote como páginas já conhecidas. Se personagens como os duques comentarão depois as aventuras publicadas do Quixote, o notável é que o personagem Orlando Furioso as comente como quem já conhece o romance que os demais passarão a ler. Como leitor de um texto ainda inédito e como interlocutor de seu protagonista.

Orlando como leitor antecipado do $Q u i-$ xote, portanto. $\mathrm{E}$ isso permite um curioso diálogo, em que ambos os heróis se tornam leitores recíprocos. Pois o tributo do Furioso, como leitor e cantor de Dom Quixote, está, por sua vez, em relação com o tributo quixotesco a Orlando Furioso. Sabemos que Dom Quixote se orgulhava de haver conhecido, na língua original, o personagem de Ariosto e de cantar suas aventuras. Ouçamos suas palavras: "Yo - dijo don Quijote - sé algún tanto de el toscano y me precio de cantar algunas estancias del Ariosto" (II, 42). E não é preciso relembrar as diversas outras vezes em que o Furioso é evocado pelo Quixote. Como diz Francisco Rico, em recente comentário a uma nova tradução espanhola do Orlando Furioso,
"Cervantes respira Ariosto por todos los poros: Urganda la Desconocida abre el Quijote recordándolo; Cide Hamete Benengeli es incomprensible sin las apelaciones del Orlando a Turpín: el vuelo de Clavileño recuerda, a ras de tierra, el viaje de Astolfo a la luna; las animosas mujeres de Cervantes tienen bastante que ver con las heroínas de Ariosto y hasta para pintar a Maritornes se echa mano de las octavas del Orlando" (4).

Esse soneto preliminar, portanto, permitirá a Cervantes criar em seu romance uma relação especular de leituras e de leitores, entre Dom Quixote e Orlando Furioso.

O soneto, aliás, cria outra situação literária original. Temos, por um lado, que Orlando Furioso assiste à criação do Quixote. Mas é possível dizer também que o Quixote assiste aqui ao nascimento de outro Orlando Furioso. Não sei se os estudiosos de Ariosto se deram conta do que representa esse soneto cervantino na história da recepção do poema. Essa é talvez a primeira grande ocasião em que o personagem do poeta italiano aparece recriado. Recriado como personagem de outra grande obra literária. Se admitirmos, como parece provável, que Ariosto começou a trabalhar no poema cem anos antes da publicação do Quixote, por volta de 1505, teremos que um século depois o Orlando Furioso renasce como personagem recriado por Cervantes, para viver a aventura de ser leitor do Quixote, de entrar em diálogo com o cavaleiro manchego e de ser um dos primeiros a lhe reconhecer a grandeza.

$\mathrm{Na}$ relação estreita entre os dois cavaleiros o que se torna elo privilegiado é o processo de leitura. Temos aqui dois leitores que se tornam loucos. Pois ao se evocar o Furioso, a nota da loucura assume evidência no soneto. Não é qualquer versão do Orlando que se evoca: é a que o apresenta como louco. De fato, o destino do Orlando histórico, sobre o qual pouco sabemos, foi tornar-se protagonista de grandes poemas, desde a Chanson de Roland até as obras de Pulci e Boiardo, na Itália do século XV. As-
4 Francisco Rico, "La Furia de la Ficción" Iresenha à tradução do Orlando Furioso por José María Micó), in El País, 14/5/2005 p. 10 lagradeço esta indicação à colega profa dra Concha Piñero Valverdel. 
sim, bastava que o soneto preliminar fosse atribuído a Orlando, sem qualquer adjetivo, para que nos pusesse diante de um glorioso leitor das gloriosas aventuras do Quixote. Entretanto, o que chama a atenção é que o leitor recriado pelos versos cervantinos seja o Orlando Furioso e não outro. Adedicatória do soneto o deix a claro: "Orlando Furioso a Don Quijote de la Mancha”. É o louco imaginado por Ariosto que Cervantes quer como leitor e apresentador de seu Dom Quixote. Bem por isso o Orlando do soneto lembrará ao Quixote a loucura comum: “tú, como yo perdiste el seso".

Dois leitores loucos, portanto. E mais ainda, dois leitores que chegam à loucura por meio da leitura. De início se lembrava que Dom Quixote enlouquece entre seus livros e agora basta dizer que também Orlando enlouquece por meio da leitura. Torna-se Furioso quando lê as declarações de amor trocadas entre sua amada Angélica e seu rival Medoro.

Nesse soneto, como se vê, os leitores do Quixote somos uma vez mais remetidos ao poema de Ariosto. Já vimos algumas perspectivas abertas por essa indicação de Cervantes. Outras poderiam ser recordadas se houvesse tempo. Para não me demorar, fico somente numa questão pontual de interpretação. No fecho desse soneto o Furioso convida o Quixote a domar o mouro e o cita, que os chama iguais em amores. A alusão ao "soberbio moro" e ao "cita fiero" à primeira vista é um tanto estranha. Nem tanto pela referência ao mouro, figura de importância em Ariosto e em Cervantes. Mas parece um tanto obscuro o motivo da alusão ao cita.

Os comentaristas em geral não costumam deter-se nessas palavras, ou se limitam a propor, como interpretação, que todo o soneto seria disparatado e que, portanto, não haveria que procurar explicação mais precisa. Nas palavras de Adrienne L. Martín, “los desvaríos de Orlando Furioso sólo tienen sentido cuando uno se da cuenta de que versifica desde el fondo de su locura amorosa" (5).
Contudo, outra leitura parece possível. Não estaríamos diante de alusões disparatadas, que falam no cita como poderiam falar no egípcio ou no persa. Pode-se pensar que Cervantes encerra os versos com outra referência precisa ao poema de Ariosto. $\mathrm{O}$ fecho do soneto parece aludir, precisamente, a dois grandes rivais de Orlando no amor de Angélica. O “soberbio moro” seria Ferraú, duas vezes rival de Orlando: como apaixonado pela bela princesa e como pretendente ao elmo conquistado por Orlando, o elmo de Mambrino, o mesmo que o Quixote depois haveria de vislumbrar na bacia de barbeiro. O outro rival de Orlando no amor de Angélica é o Sacripante, apresentado por Ariosto como rei da Circássia, região próxima ao Mar Negro e outrora habitada pelos citas. Este seria, pois, o "cita fiero". Sacripante e Ferraú se encontrarão com Orlando no palácio encantado donde saem em busca da princesa, que se torna invisível pelo poder da magia. Orlando vence os rivais em tudo, menos no amor, pois. Angélica não se entregrá a nenhum deles, mas ao jovem Medoro. Os três sofrem a desventura de viver em busca de sua dama, sem nunca a alcançar.

Assim, a alusão dos versos ao "moro" e ao "cita" parece antecipar episódios como o do bacielmo e o da Dulcinéia encantada, comoAngélica, pelas artes mágicas e em vão procurada pelo Quixote. Se nos lembrarmos disso ao lermos o soneto, talvez fiquem mais claras as palavras que dizem que o mouro e o cita consideram Orlando e o Quixote “iguales en amor con mal suceso".

Mas é tempo de concluir. Digamos então, uma vez mais, que os versos preliminares do Quixote merecem leitura atenta, não menos que o romance que antecedem. Digamos também que esse soneto em que o Orlando Furioso aparece recriado, como leitor e cantor do Quixote, além da atenção especial que apresenta para a análise erudita, assume valor ainda maior: é o testemunho do diálogo entre dois escritores geniais e suas imortais criações literárias: Orlando Furioso e Dom Quixote de la Mancha. 

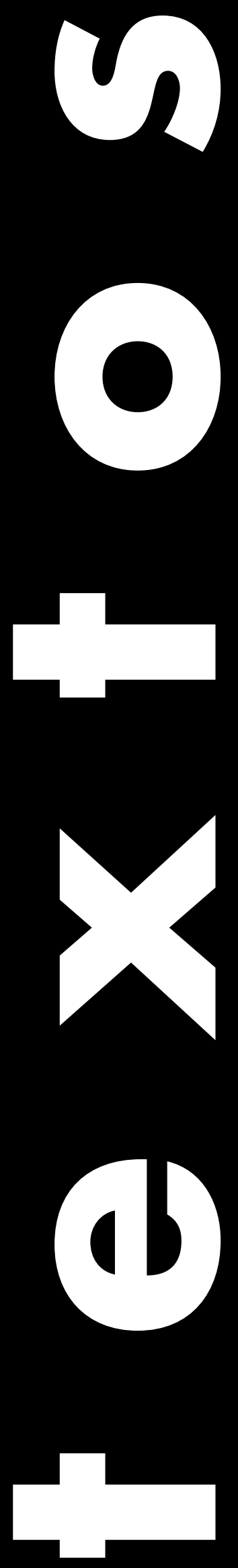